\title{
Asistan Hekimlerin Akılcı Antibiyotik Kullanımı Konusunda Bilgi ve Tutumları
}

\author{
Knowledge and Attitudes of Residents About Rational Antibiotic Use \\ Didem YILMAZ AKÇAY' (IDD), Selcen ÖNCÜ² (IID)

\footnotetext{
${ }^{1}$ Aydın Adnan Menderes Üniversitesi Araștırma ve Uygulama Hastanesi, İnfeksiyon Hastalıkları ve Klinik Mikrobiyoloji Anabilim Dalı, Aydın, Türkiye

${ }^{2}$ Aydın Adnan Menderes Üniversitesi Tıp Fakültesi, Tıp Eg̃itimi Anabilim Dalı, Aydın, Türkiye
}

Makale atıf: Yılmaz Akçay D, Öncü S. Asistan hekimlerin akılcı antibiyotik kullanımı konusunda bilgi ve tutumları. FLORA 2021;26(4):697-703.

\section{ÖZ}

Giriş: Günümüzde, akılı olmayan antibiyotik kullanımı nedeni ile antibiyotiklere karşı direnç gelişimi küresel bir sorun halini almaktadır ve toplum sağlığı için büyük bir tehdit olarak görülmektedir. Bu araştırma, üçüncü basamak sağlık kuruluşlarında yoğun hasta teması olan asistan hekimlerin akılcı antibiyotik kullanımı konusunda bilgi, yeterlik algıları ve tutumlarını belirlemek amacıyla yapılmıştır.

Materyal ve Metod: Bu araştırma, tanımlayıcı nitelikte olup, Aydın Adnan Menderes Üniversitesi Uygulama ve Araştırma Hastanesinde, çalıșmaya katılmaya gönüllü 258 asistan hekim ile gerçekleştirilmiștir. Verilerin toplanması, araştırmacılar tarafından asistan hekimlerin akılı antibiyotik kullanımı konusundaki bilgi düzey algıları ve tutumlarını değerlendirmeye yönelik geliştirilen anket formları ile yüz yüze gerçekleştirilmiştir.

Bulgular: Asistan hekimlerin \%33.7'si (n: 87) akılı antibiyotik kullanımı konusundaki yeterliklerini iyi, \%5'i (n:13) çok iyi olarak değerlendirirken \%15.9'u (n: 41) ise geliştirilmeli olduğunu bildirmiştir. Araştırmaya katılanların \%67.1'i (n: 173) mezuniyet öncesinde, \%38.4'ü (n: 99) ise mezuniyet sonrasında akılı antibiyotik konusunda eğitim almış olduklarını, \%77.1'i (n: 199) mezuniyet sonrası eğitimleri sırasında akılı antibiyotik kullanımı konusunda eğitim almak istediklerini ve bu eğitimlerin alan uzmanı öğretim üyeleri tarafından verilmesi istediklerini belirtmiştir.

Sonuç: Ortalama hasta tanı, tedavi ve takip sayısı yüksekliği nedeni ile asistan hekimlerin akılcı antibiyotik kullanımı konusunda yeterli bilgiye sahip olmaları ve akılı antibiyotik kullanımını tutum haline getirmeleri büyük önem taşımaktadır. Mezuniyet öncesinde pek çok tıp fakültesinde yer alan akılı antibiyotik kullanımının mezuniyet sonrası eğitim programlarında da yer alması, kurumların asistan hekimlerin bu konu ile ilgili düzenli güncel bilgilere ulaşması için gerekli eğitimleri yapması önem taşımaktadır.

Anahtar Kelimeler: Akılcı antibiyotik kullanımı; Bilgi; Mezuniyet sonrası eğitim; Tıp eğitimi; Tutum 


\title{
ABSTRACT \\ Knowledge and Attitudes of Residents About Rational Antibiotic Use
}

\author{
Didem YILMAZ AKCุAY'1, Selcen ÖNCÜ²
}

\author{
${ }^{1}$ Department of Infectious Diseases and Clinical Microbiology, Aydın Adnan Menderes University, Aydın, Turkey \\ ${ }^{2}$ Department of Medical Education, Aydın Adnan Menderes University Faculty of Medicine, Aydın, Turkey
}

\begin{abstract}
Introduction: Today, the development of resistance to antibiotics due to unreasonable use of antibiotics is seen as a global problem and a major threat to public health. This study was interpreted to determine the knowledge, competence perceptions and attitudes of residents who have intense patient contact in tertiary healthcare institutions about rational use of antibiotics.
\end{abstract}

Materials and Methods: This descriptive study was conducted in Aydın Adnan Menderes University Application and Research Hospital with 258 residents who volunteered to participate in the study. Data collection was carried out face-to-face by the researchers with questionnaire forms in order to evaluate the perceptions and attitudes of the residents on the rational use of antibiotics.

Results: While 33.7\% (n: 87) of the residents evaluated their competence in rational use of antibiotics as good, 5\% (n: 13) evaluated as very good and $15.9 \%(n: 41)$ reported that it should be improved. Of the participants, $67.1 \%$ ( $n: 173)$ received training about rational antibiotics during undergraduate education, $38.4 \%$ ( $n: 99)$ after graduation, $77.1 \%(n: 199)$ stated that they want to receive training on the use of antibiotics during their postgraduate education. They want these trainings to be given by faculty members who are experts in this field.

Conclusion: Due to the high number of diagnoses, treatments and follow-ups on average, it is of great importance for residents to have sufficient knowledge about rational use of antibiotics and to have a rational antibiotic use attitude. It is important to include rational use of antibiotics in many medical faculties before graduation in post-graduation training programs and to provide necessary trainings for institutions to reach regular updated information on this subject.

Key Words: Rational antibiotic use; Knowledge; Postgraduate education; Medical education; Attitude

\section{GíRiş}

Dünyada hastalıkları tedavi etmek için kullanılan ilac sıralamasında ilk sırada yer alan ve sağlık hizmetleri için önemli bir unsur olan antibiyotikler, bakteri etkenli infeksiyonlarda bakterileri öldürmek veya coğalmasını durdurmak için kullanılan ilaçlardir ${ }^{[1]}$.

Akılcı antibiyotik kullanımı, hastaların bireysel özelliklerine göre doğru antibiyotiğin; hastaya en uygun yoldan, etkin dozda, optimum aralıklarla ve uygun süreyle, ulusal ekonomiye en uygun sekilde verilmesidir. Akılcı antibiyotik tedavisi, hastalık siddeti ve süresini kısaltarak hasta sağ kalımının artırılması, komplikasyon gelișmemesi ve hastaloğın kronikleșmesinin önlenmesi için gerekli ve önemli bir durumdur ${ }^{[2]}$.

Antibiyotiklerin endikasyon dıṣı ve sık kullanımı, kullanım süresinin doğru belirlenmemesi bakterilerin sonraki tedavilere karșı direnç göstermesine neden olabilmektedir. Hizla gelișen antimikrobiyal direnc, infeksiyonların tedavisinin zorlașmasına, antibiyotiklere yanıt alınamamasına, daha fazla antibiyotik kullanılmasına, tedavi sürelerinin uzamasına, maliyetin artmasına ve hastaların hayatını kaybetmesine neden olabilmektedir ${ }^{[3,4]}$. Bakteriyel infeksiyonlara karșı en önemli silahımız olan antibiyotiklere direnc gelișimini önlemek için antibiyotikleri doğru kullanma konusunda toplum olarak farkındalı̆̆ı artırmak gerekmektedir. Ülkemizde, Reçete Bilgi Siteminden yararlanılarak elektronik ortamda yazılan reçeteleme davranıșları incelendiğinde; 2011 yllında birinci basamakta recete edilen 439.539 .673 kutu ilacin \%12.71'inin (55.878.010 kutu) antibiyotiklerden oluștuğu tespit edilmiștir. Reçetelerin maliyet analizleri yapıldığında maliyetin \%14.14'ünü antibiyotiklerin olușturduğu görülmektedir. Bu durum ülkemizdeki ilac tüketiminde önemli bir yeri olan antibiyotiklerin akılcı kullanımının önemini açıkça göstermektedir. Antibiyotiklerin akılcı kullanılmaması tüm dünyada hastaların tedaviye uyumunun azalmasına, ilac etkileșimlerine, antibiyotiklere karșı direnc gelismesine, hastalıkların tekrarlamasına ya da uzamasına, 
karșıt olay görülme sıklığının artmasına ve tedavi maliyetlerinin artmasına neden olabilen ciddi bir halk sağlığı sorunudurr ${ }^{[5,6]}$. Akılcı antibiyotik kullanımında devletin, ilaç endüstrisinin, hekimlerin, hemșirelerin, eczaciların ve toplumun akılcı davranması gerektirmektedir ${ }^{[7]}$. Akılc1 antibiyotik kullanımının en önemli halkalarından olan hekimlerin doğru ve güncel bilgilere sahip olmaları önem tașımaktadır.

Bu çalıșmada Aydın Adnan Menderes Üniversitesi Araștırma ve Uygulama Hastanesinde hasta tanı, tedavi ve takibinde görev alan asistan hekimlerin akılcı antibiyotik kullanımı konusundaki bilgi yeterlik algıları ve tutumlarına ilișkin değerlendirmelerin yapılması ve konu ile ilgili eğitim gereksinimlerinin belirlenmesi amaclanmıstır.

\section{MATERYAL ve METOD}

$\mathrm{Bu}$ araștırma, nicel, betimleyici bir araștırma olup Ekim 2018-Haziran 2019 tarihleri arasinda Aydın Adnan Menderes Üniversitesi Araștırma ve Uygulama Hastanesinde gerçekleștirilmiștir. Araștırmanın evrenini; Dahili ve Cerrahi Bölümlerde görev yapmakta olan 356 asistan hekim olușturmaktadır. Araștırmada örneklem seçimine gidilmeden çalıșmaya katılmaya gönüllü 258 asistan hekim çalıșmaya dahil edilmiștir.

Veri toplama aracı olarak; literatür taramaları ıșığında, araștırmacılar tarafından geliștirilen anket formu kullanılmıștır. Anket formu iki bölümden olușmaktadır. Birinci bölüm katılımcıların sosyo-demografik özelliklerini belirlemeye yönelik sorulardan olușmaktadır. Bu bölümde hekimlerin görev yapmakta oldukları bölüm, bölümde ne kadar süredir görev yaptıkları, lisans mezuniyet yılları, birinci basamak sağlık kurulușunda calıșma tecrübeleri, mezuniyet öncesinde ve sonrasında akılcı antibiyotik kullanımı konusunda eğitim alma durumları, mezuniyet sorasında eğitim aldılarsa eğitimi nereden aldıkları ve akılcı antibiyotik kullanımı konusundaki yeterliliklerini nasıl algıladıkları sorulmuștur. İkinci bölümünde ise, akılc1 antibiyotik kullanımı konusundaki bilgi düzeylerini nasıl algıladıkları ve tutumlarını belirlemeye yönelik sorular sorulmuștur. Bu bölümde katılımcıların; antibiyotik reçete etme sıklıkları, reçete ederken yararlanılan kaynaklar, antibiyotiklerle ilgili bilgi düzeylerini nasıl algıladıkları, antibiyotik reçete etme durumları, hasta bilgilendirmeleri, hasta bilgilendirmeleri sonrası anlașılıp anlașılmadıklarının kontrolü ve akılcı antibiyotik kullanımı konusunda eğitim alma gereksinimleri ve eğitimleri kimlerden almak istedikleri sorulmuștur.

Anket formları ile toplanan veriler SPSS veri tabanına aktarılarak analiz edilmiștir. Veri analizinde dağılımları belirlemede; yüzde, frekans, aritmetik ortalama, standart sapma; değișkenlere göre olușan farkın belirlenmesinde ise parametrik (t, F) testler kullanılmıștır. İstatistiksel anlamlılık düzeyi olarak $\mathrm{p} \leq 0.05$ kabul edilmiștir.

Calıșma için, Aydın Adnan Menderes Üniversitesi Tip Fakültesi Girișimsel Olmayan Klinik Araștırmalar Etik Kurulu onayı (Etik kurul no:2018/1483) alınmıștır.

\section{BULGULAR}

$\mathrm{Bu}$ çalıșmada, yaș ortalaması $28.63 \pm 0.19$ y1l olan (min 24 - maksimum 51), \%48.1'i (n: 124) kadın, \%51.9'u (n: 134) erkek, toplam 258 asistan hekim yer almıștır. Calıșmaya katılanların \%72.9'u (n: 188) dahili, \%21.1'i (n: 70) Cerrahi birimlerde calıșmaktadır. Calıșmaya katılanların \%65.1'i (n: 168) birinci basamak sağlık kurulușunda çalıșma tecrübesine sahip olduğunu bildirmiștir.

Calıșmaya katılanların \%67.1'i (n: 173) mezuniyet öncesinde, \%38.4'ü (n: 99) mezun olduktan sonra akılcı antibiyotik konusunda eğitim almıș olduklarını bildirmiștir. Mezuniyet sonrası eğitimin \%19'u (n: 49) Sağlık Bakanlığınca düzenlendiği, \%14.3'ünün ( $n$ : 37) ise mezuniyet sonrası eğitim kapsamında verilmiş olduğu belirtilerek diğer eğitim kaynakları Tablo 1'de belirtilmiștir. Calıșmaya katılanların \%77.1'i (n: 199) mezuniyet sonras1 eğitimleri süresince akılcı antibiyotik kullanımı konusunda eğitim alma gereksinimi duyduklarını belirtmiștir. Bu eğitimlerin kimlerce verilmesini istedikleri sorgulandığında; \%52.9'u (n: 134) bu eğitimleri alan uzmanı öğretim üyelerinden, \%3.5'i (n: 9) ise mesleki tecrübesi fazla olan öğretim üyelerinden almak istediklerini belirtmișlerdir. Katılımcıların antibiyotik reçete etme sıklikları; \%2.3 (n: 6) cok sik, \%13.6 (n: 35) sik, \%47.7 (n: 123) orta, \%21.7 (n: 56) az ve \%14'ü (n: 36) ise hiç olarak belirtilmiștir.

Calıșmaya katılanların \%62.4'ü (n: 161) antibiyotik reçete ederken bilgi alabilecekleri fark- 
Tablo 1. Asistan hekimlerin akııı antibiyotik konusundaki eğitim durumu

\begin{tabular}{lcc} 
& $\mathbf{n}$ & $\%$ \\
\hline Mezuniyet öncesi akılıı antibiyotik eğitimi alma durumu & 173 & 67.1 \\
Mezuniyet sonrası akılcı antibiyotik eğitimi alma durumu & 99 & 38.4 \\
Mezuniyet sonrası eğitim içeriği olarak & 37 & 14.3 \\
Sağlık Bakanlığınca düzenlenen eğitimler & 49 & 19.0 \\
İlaç firmalarınca düzenlenen eğitimler & 11 & 4.3 \\
Özel olarak alınan eğitimler & 7 & 2.3 \\
Meslek odası eğitimleri & 2 & 0.8 \\
Mezuniyet sonrası akılcı antibiyotik eğitimi alma gereksinimi & 199 & 77.1
\end{tabular}

l1 kaynaklara ihtiyac duyduklarını belirtmiștir. Bu kaynaklar; \%19.6 (n: 49) internet ve internet kökenli kaynaklar, \%10.8'i (n: 27) Vademecum, \%6.8 (n: 16) tıp kitapları, \%3.6 (n: 10) kilavuzlar ve $\% 0.8$ 'i (n: 2) ders notları, \%0.4'ü (n: 1) diğer hekimler olarak sıralanmıstır.

Katılımcıların \%5’i (n: 13) akılc1 antibiyotik konusundaki yeterliliklerini cok iyi, \%33.7'si (n: 87) iyi, \%45'i (n: 136) orta, \%15.9'u (n: 41) ise gelistirilmeli olarak algıladıklarını belirtmiștir.

Calıșmaya katılanların \%74'ü (n: 191) hastay1 muayene etmeden ilac reçete etmediklerini, $\% 12.8$ 'i (n: 33) sadece kronik hastalkkların ilaclarında bunu yaptıklarını bildirmiștir.

Katılımciların \%90.3'ü (n: 233) hastalara antibiyotik kullanımı ile ilgili bilgi vermenin önemli olduğunu ifade ederken \%9.3’ü (n: 24) hastalara antibiyotik kullanımı ile ilgili bilgi vermeye gerek görmediklerini belirtmiștir. Katılımcıların \%41.1’i (n: 106) her hastada, \%37.6's1 (n: 97) ise yalnız kullanımı özen isteyen antibiyotik reçete ettikleri hastaya kullanacağı antibiyotikle ilgili bilgi verdikten sonra anlașıldığını kontrol ettiğini belirtirken \%13.6's1 (n: 35) yeterli zamanı olmaması nedeni ile, \%7.4'ü ise (n: 19) eczanede anlatılacağı için buna gerek duymadığını belirtmiștir.

Calıșmaya katılanların hastalara antibiyotik ve kullanımı ile ilgili verilen bilgilendirmeye ait konular Tablo 2'de gösterilmiștir.

Katılımciların \%49.6's1 (n: 128) hastaların antibiyotik tedavisine uyumunu artırmak için antibiyotik kullanımı konusunda halk eğitimleri düzenlenmesini, \%4.7'si (n: 12) ise kitle iletișim araçlarının kullanılmasını önermiștir.

Katılımcıların antibiyotik kullanımına iliskin farmakolojik özellikler, endikasyonlar, pozoloji ve uygulama sekli, kontredikasyonlar, yan etkiler gibi farklı alanlarda bilgilerini ne kadar yeterli gördükleri incelenmiștir. Bilgi düzeylerini en iyi buldukları alan antibiyotik endikasyonları (\%46.9 iyi) iken en

Tablo 2. Hastaya reçete edilen antibiyotikle ilgili verilen bilgiler

\begin{tabular}{lcc} 
Hasta bilgilendirme konusu & $\mathbf{n}$ & \% \\
\hline Tedavi süresi & 236 & 91.5 \\
Günlük dozu & 225 & 87.2 \\
Uygulama şekli & 213 & 82.6 \\
Antibiyotiğin olası yan etkileri & 179 & 69.4 \\
Antibiyotiği ne zaman bırakması gerektiği & 155 & 60.1 \\
Antibiyotik adı & 142 & 55.0 \\
Diğer ilaçlarla/besinlerle etkileşimi & 131 & 50.8 \\
Uzak durması gereken aktiviteler & 90 & 34.9 \\
Antibiyotiğin etki mekanizması & 38 & 14.7
\end{tabular}


Tablo 3. Asistan hekimlerin antibiyotiklerle ilgili bilgi düzey algıları

\begin{tabular}{|c|c|c|c|c|c|}
\hline & Çok iyi & İyi & Orta & Kötü & Çok köti \\
\hline Antibiyotiklerle ilgili bilgi alanları & $\%$ & $\%$ & $\%$ & $\%$ & $\%$ \\
\hline Farmakolojik özellikler & 1.9 & 27.5 & 57.4 & 12.8 & 0.4 \\
\hline Endikasyonlar & 5.4 & 46.9 & 43.8 & 2.7 & 1.2 \\
\hline Pozoloji ve uygulama şekli & 5.0 & 43 & 45.0 & 6.2 & 0.8 \\
\hline Kontredikasyonlar & 4.3 & 27.5 & 56.2 & 11.2 & 0.8 \\
\hline Yan etkiler & 2.3 & 29.2 & 57.8 & 16.3 & 0.8 \\
\hline İlaçların etkileşimleri & 1.6 & 12.8 & 49.6 & 32.6 & 3.5 \\
\hline Özel durumlar & 6.2 & 30.6 & 46.1 & 15.5 & 1.6 \\
\hline Uyarılar ve önlemler & 3.5 & 27.5 & 54.3 & 13.6 & 1.2 \\
\hline Biyoeşdeğerlilikler & 3.1 & 24.4 & 49.2 & 19.8 & 3.5 \\
\hline Antibiyotiklerin piyasa isimleri & 7.0 & 33.7 & 43.8 & 12.0 & 3.5 \\
\hline
\end{tabular}

yetersiz alan antibiyotiklerin diğer ilaçlar ve besinler ile etkileșimi (\%32.6 kötü) olarak saptanmıștır (Tablo 3).

\section{TARTIȘMA}

Dünya Sağllk Örgütü'nün 1985 yılında Nairobi'de yapmıs olduğu akılcı antibiyotik kullanımı toplantısında, akılcı antibiyotik kullanımın yaygınlașması ve sürdürülebilmesi için hekimlerin antibiyotiklerin farmakolojik özelliklerine hBkim olmaları gerekliliği ve hastalarla iletișimlerinde aktif olarak yeterli bilgilendirmeleri yapmalarının önemi vurgulanmıștır. Bunun yanında bașta hekimler olmak üzere, eczacılar, diğer sağlık çalıșanları ve toplu$\mathrm{mu}$ akıllı antibiyotik kullanımı konusunda bilgilendirilmek ve bu konuda düzenli eğitimler verilmesi önerilmiștir ${ }^{[8]}$.

Parlak'n "KOAH Akut Alevlenmesinde Kullanılan Antibiyotiklerin Akılcı İlaç Kullanımı Yönünden Değerlendirilmesi” isimli tezinde, antibiyotik gruplarının etkinliği, yoğunluğu, güvenilirliği ve maliyetleri incelenmiștir. En cok tercih edilen antibiyotiklerin tedavi sonunda belirtilerdeki azalma iyileșme oranı en yüksek, kamu maliyeti ve ortalama maliyeti en düșük ilaç grubu olduğu görülmüsstür. Bu da hekimlerin doğru endikasyon, doğru ilaç ve uygun maliyet açısından akılcı antibiyotik kullanımlarını doğrulamıștır ${ }^{[8]}$. Bulut ve arkadașlarının "Resident Doctors' (Branch) Attitudes and Behaviours About Rational Drug Use" isimli calıșmasında Ankara Il Eğitim ve Araștırma Hastanelerinde eğitim alan asistan hekimlerin akılcı ilac kullanımı konusunda bilgi ve tutumları incelenmiștir. Calıșmada hekimlerin \%2.23’ü (n: 4) akılcı ilac kullanımında kendilerini cok yeterli, $\% 35.75$ 'i (n: 64) yeterli, \%54.19'u (n: 97) orta düzeyde yeterli, \%7.84'ü (n: 14) yetersiz olduklarını belirtmișlerdir ${ }^{[9]}$. Calıșmamızda da benzer sekilde asistan hekimlerin yaklașık \%83.5'inin akılc1 antibiyotik kullanımı konusunda kendilerini orta ve üzeri yeterlilikte gördükleri belirlenmiștir.

Bulut ve arkadașlarının çalıșmasında 180 asis$\tan$ hekimin \%65.56'sının (n: 118) hastaya ilac recete ederken tedaviye cevabin nasıl ve hangi sekilde olabileceğini açıladığı, \%41.67'sinin (n: 75) muayene etmeden asla reçete yazmadığı, antibiyotik bilgisi olarak kendilerini en yetersiz buldukları alanın ise ilaç fiyatları olduğu \%10.43 (n: 17) tespit edilmiștir. Ayrıca calıșmada akılcı antibiyotik kullanımına ilișkin bilincin artması için örgün ve yaygın eğitimin düzenlenip geliștirilmesi ve idari düzenlemelerin yapılması gerektiği vurgulanmıștır ${ }^{[9]}$. Calıșmamızda muayene etmeden recete yazmama oranının cok daha yüksek olduğu ve hastalarını antibiyotik kullanımı konusunda bilgilendirdikleri belirlenmiștir. Asistan hekimlerin bu davranıșı gereksiz antibiyotik kullanımını önemsediklerini ve akılcı antibiyotik kullanımını desteklediklerini düșündürmektedir.

Sahin ve arkadașlarının "Sağlık Ocaklarında Calıșan Hekimlerinin Akılcı Antibiyotik Kullanı$\mathrm{m} 1$ ile İlgili Bilgi Düzeylerinin Değerlendirilmesi" isimli 475 hekimle gerçekleștirilen çalıșmada birin- 
ci basamak sağlık kurumlarında calıșan pratisyen hekimlerin akılc1 antibiyotik kullanımı konusunda zaman içinde bilgilerinin azalabildiği ve reçete yazma davranıșlarının değișebildiği ve hekimlerin \%89.6'sının akılcı antibiyotik kullanımı ile ilgili sürekli mesleki gelisim programlarının yararlı olacağını bildirdikleri belirlenmiștir. Hekimlerin, mezuniyet sonrasında bilgilerinin güncellenmesi gerekliliği, sık karșılaștıkları hastalıkların tedavisinde kullanılan ilaçlarla ilgili sürekli mesleki gelișim programlarının uygulanmasının hekimlerin motivasyonlarını artırarak akılcı ilaç kullanımı konusunda olumlu bir adım olacağı bildirilmiștir ${ }^{[10]}$. Parlak ve arkadașlarının "Aile Hekimlerinin Akılcı Antibiyotik Kullanımı Açısından Durumları: Erzurum'dan Kentsel Bir Calıșma" bașlıklı calıșmasında aile hekimlerinin antibiyotikler konusunda bilgi, tutum ve davranıșlarının değerlendirildiği çalıșmada aile hekimlerinin akılc1 antibiyotik kullanımında genel olarak yeterli olmadıkları, buna bağlı olarak antibiyotik kullanımı konusunda yanlıș tutumlar gösterdikleri, bu konuda en önemli eksiğin eğitimler ve rehberler olduğu belirlenmiștir. Calıșmanın sonucunda hekimlerin eksiklik ve yanlıșlarının belirlenerek bu konulara yoğunlașan akılcı antibiyotik kullanımı eğitim programlarının olușturulması ve ülke genelinde uygulanması gerekliliği vurgulanmıștır ${ }^{[11]}$. Bebitoğlu ve arkadașları tarafından hazırlanan "Akılcı İlac Kullanımın Boylamsal Bir Koridor Seklinde 3 Yıllık Klinik Eğitim Programına Entegrasyonu" isimli çalssmada, klinik tedavi kılavuzları ve temel ilac listeleri ile uyumlu farmakoterapi eğitiminin iyi reçete yazma alıșkanlığı için iyi olacağı, klinik durumlar üzerine yapılan eğitimlerle akılcı ilaç kullanımının daha iyi anlașlacağı belirtilmiștir ${ }^{[12]}$.

Calıșmamızda, katılımcıların \%77.1'i mezuniyet sonrasında akılcı antibiyotik kullanımı ile ilgili eğitime gereksinim duyduklarını belirtirken; katılımcıların yarısından çoğunun antibiyotik reçete ederken farklı bilgi kaynaklarına ihtiyac duymaları; mezuniyet öncesinde konu ile ilgili eğitim alma oranı \%67.1 iken mezuniyet sonrası eğitim kapsamında bu oranının \%14.3'e düșmesi de eğitim gereksinimlerini desteklemiștir. Celik ve arkadașlarının "Birinci Basamakta Akılcı İlaç Kullanımı" isimli çalıșmalarında, hekimlere düșen görevin ilaçların farmakolojik özelliklerine ve ilaçlarla ilgili güncellenen bilgilere hakim olmalar1; hastalarla etkili iletișim kurarak hastalara hastalığı, tedavisi, kullanması gereken ilaçlar, ilaçların yan etkileri ve etkileșimleri ile ilgili yeterli bilgi vermesi ve hastanın anlayıp anlamadığını kontrol etmesi gerektiği belirtilmiștir ${ }^{[13]}$. Bizim çalıșmamızda da benzer olarak asistan hekimlerin yalnız yarısına yakın bir kısmı hastaların antibiyotiği nasıl kullanacağını anlaması gerektiğini belirtmiștir. Düzenli eğitimler ile bu oranın yükseltilmesinin mümkün olabileceği düșüncesindeyiz.

Sonuc olarak, çalıșmamızda asistan hekimlerin büyük çoğunluğu akılcı antibiyotik kullanımı konusunda kendilerini orta ve üzerinde görmekte olduklarını belirterek bu konudaki eğitim gereksinimlerini belirtmiștir. Bu gereksinimin karșlanabilmesi amacı ile mezuniyet sonrası eğitim kapsamında, alan uzmanlarınca gerçekleștirilecek eğitim program tasarımlarının yapılması önem tașımaktadır. Calıșmamızda, katılımcıların bilgi edinme kaynakları olarak en fazla internet kaynaklarını kullanmaları, iș yükü fazlalığı ve zaman kısıtlıl1ğı göz önünde bulundurulduğunda eğitimlerin yüz yüze olmasının yanında web tabanlı eğitimlerin de etkili olabilecektir. Düzenli ve güncel eğitimlerin asistan hekimlerin akılc1 antibiyotik kullanımı konusunda yeterlik algılarını artırarak davranıs ve tutumlarında olumlu yönde etki yaratabileceği düsüncesindeyiz.

\section{ETIK KURUL ONAYI}

Çalıșma için, Aydın Adnan Menderes Üniversitesi Tip Fakültesi Girișimsel Olmayan Klinik Araștırmalar Etik Kurulu onayı (Etik kurul no: 2018/1483) alınmıștır.

\section{ÇIKAR ÇATIŞMASI}

Yazarlar bu makale ile ilgili herhangi bir clkar çatısması bildirmemișlerdir.

\section{YAZAR KATKISI}

Anafikir/Planlama: SÖ, DYA

Analiz/Yorum: SÖ, DYA

Veri sağlama: DYA

Yazım: SÖ, DYA

Gözden Geçirme ve Düzeltme: SÖ, DYA

Onaylama: SÖ, DYA 


\section{KAYNAKLAR}

1. Aktuğlu Y, Öztürk R, Akkan AG, Dumankar UDA, Tabak F, Mert UDA, et al. Pratikte antibiyotik kullanımı. iÜ Cerrahpaşa Tıp Fakültesi Sürekli Tıp Eğitimi Etkinlikleri Sempozyum Dizisi; Istanbul, Mayıs 1997.

2. Akalın, HE. Farmakoekonominin uygulanmasında ilaç endüstrinin rolü. Ankem Derg 2005;9(2):199-200.

3. Ekenler ş, Kocoğlu D. Bireylerin Akılcı Ilaç Kullanımıyla ilgili Bilgi ve Uygulamaları. J Hacettepe University Faculty of Nursing 2016;3(3).

4. Aş̧ı̆ı̆lu S. Hastane Infeksiyonları. Türk Hijyen ve Deneysel Biyol Derg 2007;64(1):1-3.

5. World Health Organization (WHO). Promoting rational use of medicines: core components. WHO 2002.

6. T.C. Sağlık Bakanlığı Türkiye Illaç ve Tıbbi Cihaz Kurumu. Akılcı Antibiyotik Kullanımı 2020. Erişim tarihi: 06.12.2020 Available from: http://www.akilciilac.gov.tr.

7. Hırçın Cenger D, Aksu Kapucu Ş, Altın H, Şengün Yalnız N, Altın S. Akilci Illaç Kullanimi Anket Sonuçlari Işiğinda Eğitim ihtiyaç Analizi. Med I of Suleyman Demirel University 2020;27(3).

8. Parlak N. KOAH akut alevlenmesinde kullanılan antibiyotiklerin akılcı ilaç kullanımı yönünden değerlendirilmesi (Doktora Tezi, Selçuk Üniversitesi Sağlık Bilimleri Enstitüsü). (2015).
9. Bulut B, Akkurt G. Resident Doctors' (branch) Attitudes and Behaviours About Rational Drug Use. Ankara Med J 2020;20(3):641-52.

10. Şahin H, Arsu G, Köseli D, Büke Ç. Sağlık ocaklarında çalışan hekimlerinin akılcı antibiyotik kullanımı ile ilgili bilgi düzeylerinin değerlendirilmesi. Mikrobiyol Bul 2008;42(2):343-8.

11. Parlak E, Çayır Y, Ertürk A. Aile Hekimlerinin akılcı antibiyotik kullanımı açısından durumları: Erzurum'dan kesitsel bir çalışma. Euras J Fam Med 2013;2(1):27-32.

12. Bebitoğlu BT, Gülpınar MA. Akılcı Ilaç Kullanımının Boylamsal Bir Koridor Şeklinde Üç Yıllık Klinik Eğitim Programına Entegrasyonu. Tıp Eğitimi Dünyası 18(56):110-22.

13. Çelik SB., Can H. Birinci basamakta akılcı antibiyotik kullanımı. Smyrna Tıp Dergisi 2012;1:79-81.

\section{Yazıșma Adresi/Address for Correspondence} Dr. Selcen ÖNCU்

Aydın Adnan Menderes Üniversitesi Tıp Fakültesi, Tıp Eğitimi Anabilim Dalı

Aydın-Türkiye

E-posta: selcenoncu@hotmail.com 